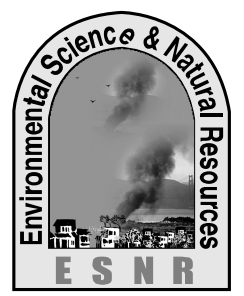

J. Environ. Sci. \& Natural Resources, 5(1): 121 - 127, 2012

ISSN 1999-7361

\title{
Hospital Waste Management in Tangail Municipality
}

\author{
M. Y. Mia, M. A. Ali, M. A. Rahman, L. Naznin and M. U. Hossain
}

Department of Environmental Science and Resource Management

Mawlana Bhashani Science and Technology University, Santosh, Tangail

\begin{abstract}
An investigation was conducted on hospital waste management in Tangail Municipality and its impact on human health. Data was collected through questionnaire interview from local residents, superintendents, nurses, observation and secondary sources. The results revealed that wastes are collected every alternative day and though sometime in irregular basis. Hospital wastes causes different health hazards like bad smell, infestation of animals, diarrhoea, skin diseases etc. due to irregular collection, unsafe handling, disposal, storage, transportation and finally dumped with municipal wastes. For knowing health impacts, among 110 general respondents $63 \%$ was affected, and 50 respondents who were associated with medical waste handling including nurse, pickers, workers, etc. in which more than $90 \%$ were affected one or more diseases due to improper management and imposed of hospital wastes. Shortage of dustbin is common in every hospitals and clinics in Tangail Municipality. The study also revealed that $1000-1500 \mathrm{~kg}$ wastes were generated per day in Tangail Municipal area in which $19.23 \%$ infectious and $80.77 \%$ noninfectious.
\end{abstract}

Keywords: Health hazard, Hospital waste, Management

\section{Introduction}

One of the major areas of today's concern is the waste management, more specifically "Hospital waste management", which has always been overlooked and thereby has produced many of the health hazards for the people in terms of morbidity and mortality. Hospital waste refers to the waste resulting directly from patient's diagnosis, prevention, research, alleviation of disablement and treatment purpose, as well as waste generated from all other departments of the health care establishment. Hospital wastes are highly infectious and hazardous. They may carry the germs of dreadful diseases like hepatitis B and C (jaundice), and HIV/AIDS. The present practice of improper handling of generated hospital wastes in Tangail Municipality (TM) is playing a contributing role in spreading out the Hepatitis and other diseases. Hospital waste accounts for a very small fraction of the total waste generated in a city. Mixed with the ordinary waste, they make the entire municipal solid waste stream a great public health hazard. The liquid and solid wastes containing hazardous materials are simply dumped into the nearest drain or garbage heap, respectively where they are prone to contaminate the rag-pickers that sift through the garbage dumps. The prevalence of diseases that may be transmitted by hospital waste is alarming in Bangladesh. The Health Care Establishment (HCE) is one of the major producers of solid wastes which are hazardous in nature. Poor management of clinical wastes exposes health workers, waste handlers and the community to infections, toxic effects and injuries
(Ecoaccess, 2004). The hazardous waste includes pathological, infectious, sharps and chemical wastes are normally produced in labour wards, operation theatres, laboratories, etc (Mato and Kaseva, 1999). Askarian et al, (2004) explained the type and nature of hospital wastes generated from private hospitals in Fars province in Iran and also describe the existing management systems of the generated wastes in hospitals. Tamplin et al, (2004) in their "Issues and options for the safe destruction and disposal of used injection materials" showed from their study in the developing countries that contaminated medical wastes find their way into municipal garbage poses obvious health risks, both in terms of direct exposure and environmental contamination. The problem is getting worse with the increasing number of hospitals, clinics, and diagnostic laboratories in the municipality. The rapid increase of private hospitals, clinics, diagnostic laboratories etc. in Tangail Municipality exerts a tremendous impact on human health ecology. More than 20 clinics and hospitals exist in the Tangail Municipality. The recent progress report on "Clean Dhaka Master Plan" conducted by the Japan International Cooperation Agency (JICA) explains about the management pattern of solid waste in Dhaka City (JICA, 2004). The JICA study team focuses the problems of handling and mismanagement of existing system of solid waste transportation and dumping. Considering these consequences, the study was conducted with the following objectives; i) to make an inventory of HCE (Health Care Establishments) in terms of government hospitals, private hospitals, private clinics, and 
pathological diagnostic centres in Tangail municipality, and ii) to quantify the amount of solid wastes generated by each HCE and iii) to identify the current hospital waste management practices (e.g. storage, collection, transportation and disposal) within the hospital premises.

\section{Materials and Methods}

Tangail is the fast growing urban area, situated 100 kilometers in the north of capital city Dhaka, along with Dhaka-Mymensingh Highway. It is one of the oldest District towns in Bangladesh which has been established in 1 July, 1887. At present the area of the TMA is $29.43 \mathrm{~km}^{2}$ and total population is around $1,28,785$ (BBS, 2001).

The data of hospital waste of Tangail Municipality was collected by investigation of the waste throwing normal dustbins and open areas. The primary data was collected from various sources and in various ways. The tool which was used to collect the primary data is questionnaire schedule from superintendent of the Hospital, Clinics and other Diagnostic centre. Different data about the hospital wastes were collected through field level inventory, questionnaire survey and interviews with doctors, nurses, superintendent, Resident Medical Officer (RMO) and Civil surgeon in hospitals and in-depth interviews with different respondents allow a greater depth of understanding of the waste management system in the study area.

The nurses, waste labours and workers were questioned through for measuring the daily waste amounts, waste types and waste sources denotation. The inmates of wards were asked in a daily basis to evaluate waste sources, hazards and problems and the actions were implemented by the Municipal authority. For the investigation of the municipality waste sources and waste problems, some locations were observed regularly by following a weeklong duration. Tangail General Hospital, Sonya clinic, Dhaka clinic and other Diagnostic centre and road sides, normal dustbins were selected to conduct the experiment. For observing health impacts, 110 respondents near the medical waste generation, storage and disposal area and 50 respondents who are associated with medical waste handling including nurse, pickers, workers, etc. were selected randomly. Data were analyzed by using software MS Excel.

\section{Results and Discussion}

Characteristics of the different respondents are shown in Table 1, 2 and 3.

Table 1. Age distribution of the respondent

\begin{tabular}{|l|l|}
\hline Age categories (Year) & Percentage (\%) \\
\hline Young (10-30) & 21.43 \\
\hline Middle (31-50) & 42.86 \\
\hline Old (51-70) & 35.71 \\
\hline Total & 100 \\
\hline
\end{tabular}

Table 2. Education of the respondent

\begin{tabular}{|l|l|}
\hline Educational status & Percentage (\%) \\
\hline Primary (1-5) & 14.29 \\
\hline SSC (6-10) & 35.71 \\
\hline HSC (11-12) & 28.57 \\
\hline Graduate (13-16) & 21.43 \\
\hline Total & 100 \\
\hline
\end{tabular}

Table 3. Category of the different respondents

\begin{tabular}{|l|l|}
\hline Category & Percentage (\%) \\
\hline Daily labor & 21.43 \\
\hline Service holder & 14.29 \\
\hline Student & 14.28 \\
\hline House wife & 28.57 \\
\hline Tokai & 21.43 \\
\hline Total & 100 \\
\hline
\end{tabular}

The study finds that total $1000-1500 \mathrm{~kg} /$ day waste materials have been measured in Tangail Municipality. The waste generation of major hospitals and clinics and their types is given in Table 4. Tangail General Hospital (TGH) is the biggest government owned hospital in Tangail Municipality. During the field survey, various hospital wastes was observed such as pathological wastes, textile stained with blood, cotton pads, used syringes, broken bottles and glass, paper, cans and other metals, vegetable/rubbish and sharp instruments (syringe-needles, surgical blades and blood lancets) etc. Some of the wastes are blood stained. All the HCE produce used syringes, broken bottles and glass, textile stained with blood and papers (Fig. 1). 


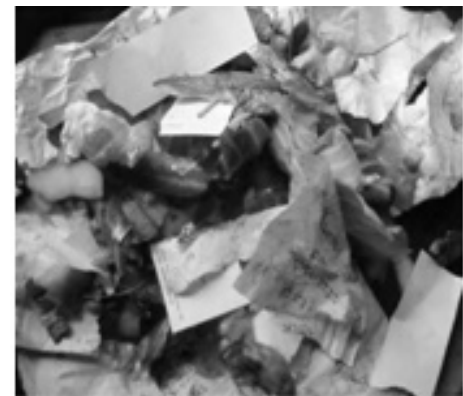

General waste

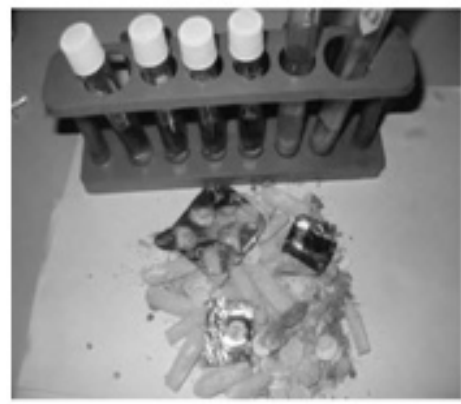

Chemical waste

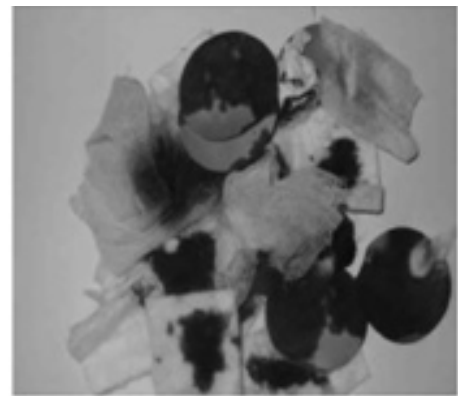

Infectious waste

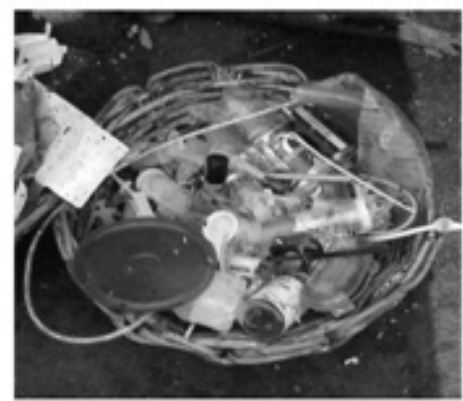

Plastic waste

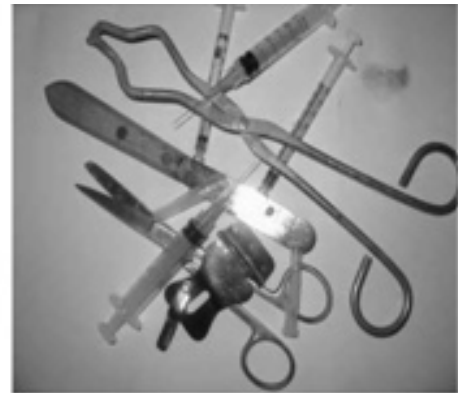

Sharp instruments

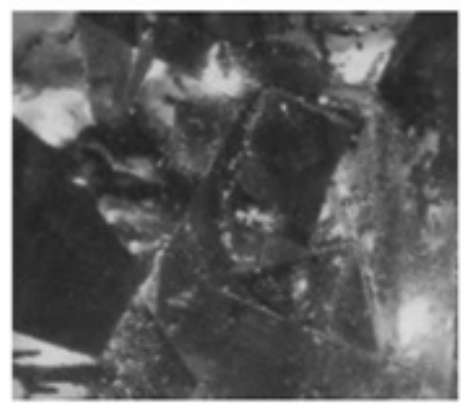

Radioactive waste

Fig. 1. Types of generated wastes identified from the field survey.

The study measured about 1.5 ton/day of wastes, of which only about 1 ton/day (80.77\%) was non- infectious wastes and about 0.5 ton/day (19.23\%) was infectious wastes.

Table 4. Proportion of different hospital wastes in Tangail municipal area

\begin{tabular}{|c|c|c|c|c|c|c|c|c|c|}
\hline \multirow{2}{*}{$\begin{array}{c}\text { Name } \\
\text { of the } \\
\text { instituti } \\
\quad \text { on }\end{array}$} & \multicolumn{5}{|c|}{$\begin{array}{c}\text { Infectious agents (in \%) } \\
\text { Total } 19.23 \% \\
\end{array}$} & \multicolumn{4}{|c|}{$\begin{array}{c}\text { Non-infectious agents (in \%) } \\
\text { Total } 80.77 \%\end{array}$} \\
\hline & $\begin{array}{l}\text { Sharp } \\
\text { instruments }\end{array}$ & $\begin{array}{l}\text { Vial- } \\
\text { ampoule }\end{array}$ & Placenta & $\begin{array}{l}\text { Body } \\
\text { fluids }\end{array}$ & $\begin{array}{c}\text { Blood/ } \\
\text { urine } \\
\text { bags }\end{array}$ & Kitchen & $\begin{array}{l}\text { Cotton } \\
\text { bandage }\end{array}$ & $\begin{array}{l}\text { Saline } \\
\text { bags }\end{array}$ & Others \\
\hline TGH & 4 & 11 & 7 & 3 & 5 & 51 & 12 & 4 & 3 \\
\hline $\begin{array}{l}\text { Soniya } \\
\text { Clinic }\end{array}$ & 3 & 9 & 15 & 3 & 4 & 47 & 8 & 5 & 6 \\
\hline $\begin{array}{l}\text { Dhaka } \\
\text { Clinic }\end{array}$ & 3 & 7 & 21 & 3 & --- & 40 & 12 & 7 & 7 \\
\hline $\begin{array}{r}\text { Sheba } \\
\text { Clinic }\end{array}$ & 5 & 7 & 5 & 2 & 5 & 41 & 16 & 13 & 6 \\
\hline
\end{tabular}


Study on hospital waste was also done by WHO (2001) and a flow diagram on that study is presented in Fig. 2.

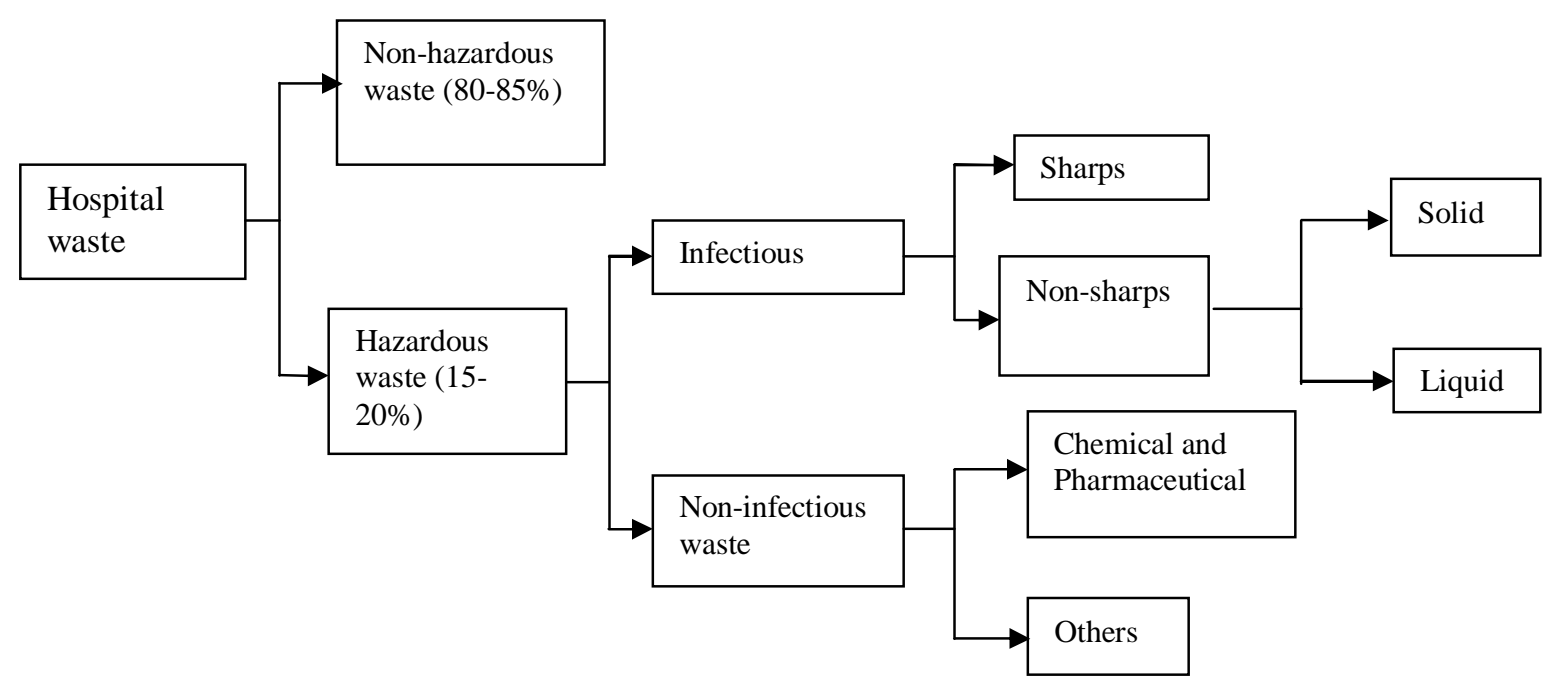

Fig. 2. Different types of healthcare waste (WHO, 2001).

The study measured about 1.5 ton/day of wastes, of which only about 1ton/day $(80.77 \%)$ was noninfectious wastes and about 0.5 ton/day $(19.23 \%)$ was infectious wastes.

\section{Waste status of Tangail General Hospital (TGH)}

The TGH is the largest government owned hospital in Tangail having almost all the health-care facilities such as pathology, radiology and imaging, microbiology, surgery, pharmacology and therapeutics, gynaecology, etc. Apart from the facilities of health-care, outdoor, emergency, OT, etc are in the TGH. The TGH has the capacity for 250 beds and about 50 floor patients. The hospital provides emergency treatment to about 25-30 patients daily, surgical treatment (major and minor operations) to about 10-15 patients per day from various departments and wards, and outdoor advice to about $100-120$ in a day. The net generation of noninfectious and infectious wastes from the TGH are calculated about $70 \%$ and $30 \%$, respectively. It is found from the fieldwork that more than half $(51 \%)$ of the generated wastes in TGH is kitchen wastes followed by cotton bandage (12\%), vial-ampoule (11\%), placenta (7\%), saline bags $(4 \%)$, sharp instruments (4\%), body fluids (3\%) and others $3 \%$.

\section{Waste status of Sonya Clinic}

The Sonya Clinic is the largest clinic in Tangail Municipality having most of the health-care facilities (e.g. pathology, surgery, gynaecology etc). Apart from the facilities of health-care, outdoor, emergency, OT, etc. are available in the Sonya Clinic. The Sonya Clinic has the capacity for 40 beds for resident patients. It has been estimated from the survey that the Sonya Clinic generates about one-eight (12.53\%) of the total wastes generated in the surveyed HCE. Almost half $(47 \%)$ of the generated waste in Sonya Clinic is kitchen wastes followed by placenta (15\%), vial-ampoule (9\%), cotton bandage (8\%), saline bags $(5 \%)$, sharp instruments (3\%), body fluids (3\%), Blood/ urine bags $4 \%$, and others $6 \%$.

\section{Waste status of Dhaka Clinic}

The Dhaka Clinic is one of the largest private Clinic in Tangail Municipality having the modern healthcare facilities. The Dhaka clinic has the capacity for 20 beds resident patients. It has been estimated from the survey that the Dhaka clinic generates slightly more than $4 \%$ of the total wastes generated in the surveyed HCE (Fig. 3). The net generation of the wastes from Dhaka clinic is $4.05 \%$, of which $3.41 \%$ is non-infectious waste and $0.64 \%$ of infectious waste having $2 \mathrm{~kg} / \mathrm{day}$ of non-infectious waste and 0.5 $\mathrm{kg} /$ day of infectious waste totalling of $2.5 \mathrm{~kg} /$ day of wastes. Some two-third (40\%) of the generated waste 
in Dhaka clinic is kitchen wastes followed by placenta $(21 \%)$, cotton bandage $(12 \%)$, vial-ampoule (7\%), saline bags (7\%), body fluids (3\%), sharp instruments $(3 \%)$, and others $7 \%$.

\section{Waste status of Sheba Clinic}

The Sheba clinic has the capacity for about 30 beds for resident patients and provides outdoor facilities for about 250 patients daily. It has been estimated from the survey that produce $14.51 \%$ of wastes generated in the surveyed HCE for this research. Approximately $8 \mathrm{~kg} /$ day $(11.84 \%)$ of non-infectious wastes and $2 \mathrm{~kg} /$ day $(2.67 \%)$ of infectious wastes totalling of $10 \mathrm{~kg} /$ day of waste has been generated from the Sheba clinic.

The clinic generate about two-third (41\%) of the kitchen wastes followed by cotton bandage (16\%), saline bags $(13 \%)$, vial-ampoule $(7 \%)$, placenta $(5 \%)$, blood and urine bags (5\%), sharp instruments $(5 \%)$, and others.

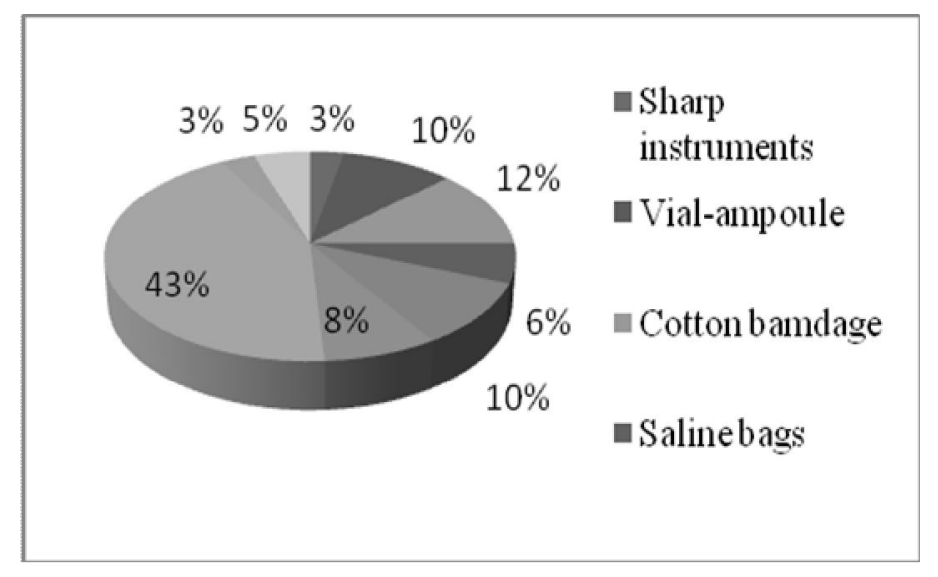

Fig. 3. Types of wastes (\%) generated in HCE.

\section{Health Impacts}

Among the 110 respondents who are associated with waste generation, storage and dumping, $63 \%$ people were affected one or more several diseases such as diarrhoeal, chloral, hepatitis $\mathrm{B}$ and $\mathrm{C}$, skin disease, infection with sharp wastes, etc. Among the 50 respondents who associated with handling medical waste, more than $90 \%$ were affected one or more of the above mentioned diseases.

In Health Care Establishment (HCE), two types of wastes are generated: non-hazardous and hazardous. The first category contains the domestic wastes in terms of paper, kitchen wastes, food wastes and others from hospital services. The second group includes wastes, which are produced in laboratories, operating rooms, consulting rooms and hospital units.

The Sheba clinic produces the average waste generation rate of $10 \mathrm{~kg} /$ day, more than those of the Dhaka clinic and Sonya clinic. In some HCE, radioactive, infectious, and sharp wastes are separated from the non-infectious waste at the site of production and they are not stored in similar containers and are disposed together. In all hospitals, pharmaceutical waste and pressurized containers are disposed along with the general waste. Liquid pharmaceutical waste is poured into the drains along with liquid chemical waste. Most of the HCE do not have plastic bags and strong plastic containers for infectious waste in accordance with the WHO guideline (WHO, 2001). Intermingling of dangerous wastes with general waste in the hospitals is due to the lack of comprehensive staff training and to a lesser extent due to the lack of facilities. There is no segregation system for infectious and non-infectious waste stream at the site of production almost in all the HCE. A total of $91.53 \%$ do not segregate the waste, but they have special storage before disposing them into the roadside Tangail Municipality (TM) bin. The research also reveals that all the HCE in the study site finally dispose their wastes into the TM bin. The $\mathrm{TGH}$, and other clinics dispose their wastes into the TM bin without segregating them. This poses serious health risks to the personnel handling the waste and to the scavengers at the dumpsite and the public at the 
large site. In the TM, the study found some cleaners to be segregating syringe-needles, saline bags, empty water bottles, tubes etc. for sale and reuse (Fig. 3). The place/storage where the hospital waste is kept before transporting to the TM bin is termed as a temporary waste storage. Some small HCE do not have any temporary storage and they simply disposed the waste into the TM bin. Most of the HCE keep their waste in different designed bins located in the corner of the hospital yard until disposing into the $\mathrm{TM}$ bin. It is noted here that all the wastes generated in the HCE finally intermingled when disposing them to the TM bin. It was found that shortage of dustbin is common in every hospitals and clinics in Tangail Municipality.

Wastes from the Operation Theatre (OT) and Intensive Care Units (ICU) are collected more often, depending on the number of operations and cases attended in any particular day. Apart from the TGH, almost all the HCE collect their wastes in different times depending on the amount of wastes are to be generated. In the Pathology Department (PD), the generated wastes, most importantly, syringes and the needles with which they take the blood samples are collected in a box after use. Then they hand it over to the sweepers and cleaners. In the Gynaecology Department, the generated wastes are collected into the metal dustbin for disposing into the TM bin. There were sanitary napkins, leftover food, liquid wastes, placenta, disposable gloves etc. All the generated wastes go inside the same dustbin and nothing is segregated. Sweepers collect the syringes and saline bags from them. The Operation Theatres (OT) in HCE produce catheters, gauze, blood cottons, etc. The syringes and saline bags are kept separately with the HCE since they are returned again to the hospital suppliers.
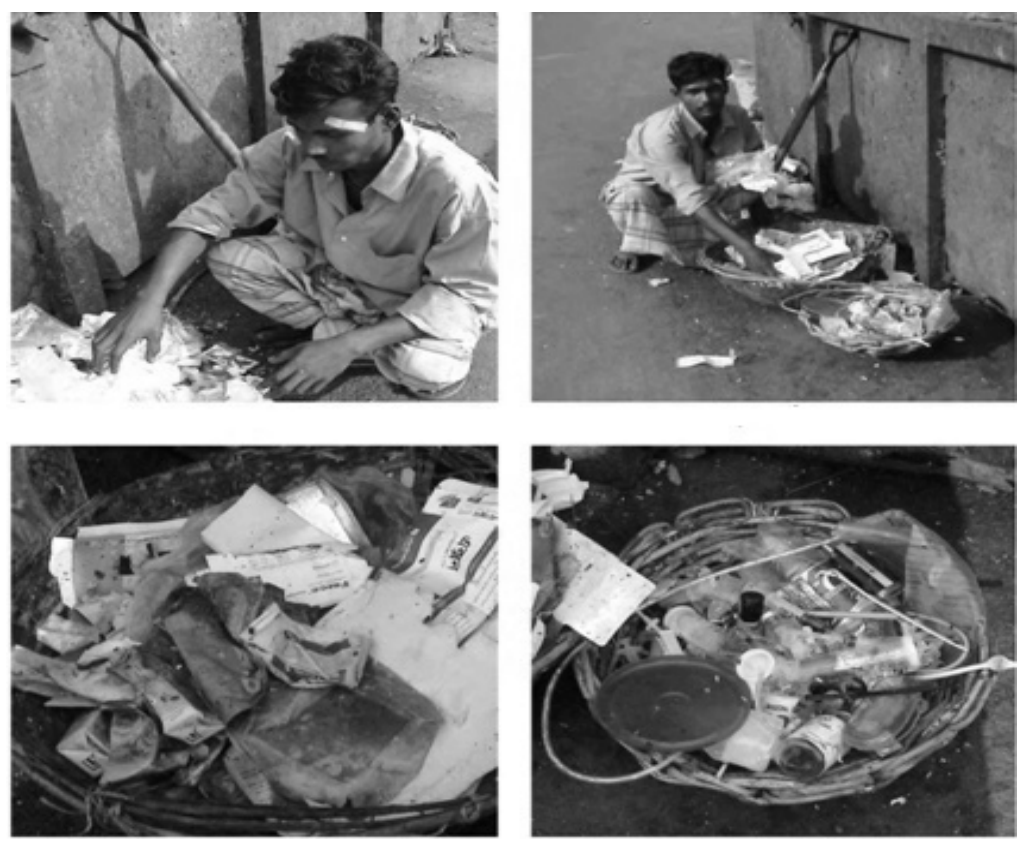

Fig. 4. Unsafe handling and Segregation of various hospital wastes

\section{Conclusions}

Almost $93 \%$ of the HCE from our study site collect and dispose their waste into the TM bin. At the end of each shift, hospital waste is collected and transported to a bin for temporary storage by hospital cleaners. In some HCE, closed containers are used for off-site transport of waste from the sites of production (different wards) to the TM bin. The TM has the responsibility for off-site transport of the waste for final disposal or dumping. It is noted here that off-site transport to the roadside TM bin is undertaken by the hospital staff. Hospital wastes management today is considered to be one of the most serious problems in Tangail Municipality. The problem continues since the log period of time due to the failure and inefficiencies of the Hospital authority, Municipality as well as the lack of awareness of the local people. 
The study revealed that the conventional methods and practices of managing hospital wastes have failed to manage the increased waste heaps generated by the economic, commercial and health care activities such as handling, storage, depose/dumping, etc. of the municipality. The proper management of hospital waste is seemed to be the most immediate and serious problem for the urban communities, where the rapid trends of urbanization aggravated the situation. It can be concluded from the study that the hospital waste management is improper such as handling, storage, collection, dispose/ dumping and which increase the potential health and environmental risk in Tangail Municipal Area.

In order to arrange a proper and systematic in-house waste management, the following recommendations may be considered; i) avoid the risk of health effect from the wastes, it needs to formulate proper policy regarding this issue, ii) the fact is that there has not been any municipal waste treatment in Tangail yet, and the generated wastes have been dumped on municipal dumping grounds by the Tangail Municipality. It is essential to treat the infectious waste before dumping them into the TM dumping grounds, iii) the health care waste management issue is becoming critical in view of the growing amounts of health care risk waste and fast increasing HIV/AIDS incidence among certain groups. Arrangement of training regarding this issue could minimize the health risk. Moreover, the training could increase attention to blood safety, disposal of needles and syringes and other infectious waste. iv) hospital wastes are needed to be segregated separately, according to its characteristics, at the point of generation. All the HCE should use the WHO permitted colour-coded, high-density polyethylene bags for easy identification and segregation of biomedical solid waste, and v) a remedial measure with the installation of a environment friendly incinerator in the city.

\section{References}

Askarian M; Vakili M; and Kabir G., 2004. Results of a hospital waste survey in private hospitals in Fars province, Iran. Waste management, 24: 347-352.

BBS (Bangladesh Beauro of Statistics, 2001. Bangladesh Population Census; Community Series, Tangail District, Dhaka.

Ecoaccess. 2004. Information sheet on waste management: Determining whether waste is "clinical waste". [www.epa.qld.gov.au].

JICA. 2004. Clean Dhaka Master Plan. Progress report, JICA: Dhaka.

Mato R. and Kaseva M. 1999. Critical review of industrial and medical waste practices in Dar-esSalaam City. Resources, Conservation and Recycling, 25: 271-287.

Tamplin, S. A. 2004. Issues and options for the safe destruction and disposal of used injection materials. Waste Management, 24: 359-364.

WHO. 2001. Health-care Waste Management: Rapid Assessment Tool for Country Level. World Health Organization: Geneva. 